Check for updates

Cite this: RSC Adv., 2017, 7, 53720

Received 23rd September 2017 Accepted 7th November 2017

DOI: $10.1039 / \mathrm{c} 7 \mathrm{ra10551g}$

rsc.li/rsc-advances

\section{Magnetic graphene solid-phase extraction in the determination of polycyclic aromatic hydrocarbons in water $\dagger$}

\author{
Liling Pang, ${ }^{a}$ Wanfeng Zhang, ${ }^{b}$ Weiya Zhang, ${ }^{c}$ Pin Chen, ${ }^{a}$ Jing Yu, ${ }^{a}$ Gang-Tian Zhu (D) ${ }^{a}$ \\ and Shukui Zhu (D)*a
}

In this work, magnetic graphene nanocomposite $\mathrm{Fe}_{3} \mathrm{O}_{4} / \mathrm{rGO}$ was fabricated by using a solvothermal method and applied to the magnetic solid-phase extraction (MSPE) of polycyclic aromatic hydrocarbons (PAHs) in environmental water samples, followed by gas chromatography-mass spectrometry (GC-MS). Several parameters affecting the extraction efficiency, such as amount of magnetic graphene, extraction time, desorption conditions, were studied in detail. The results showed that $\mathrm{Fe}_{3} \mathrm{O}_{4} / \mathrm{rGO}$ has an extremely high adsorption capacity for PAHs, only $10 \mathrm{mg}$ of the adsorbent was needed for $100 \mathrm{~mL}$ of water sample, and the PAHs could be completely desorbed with $100 \mu \mathrm{L}$ of desorption solvent. Under the optimized conditions, a good linearity was obtained in the concentration range of $0.005-5 \mu \mathrm{g} \mathrm{L}^{-1}$ for 10

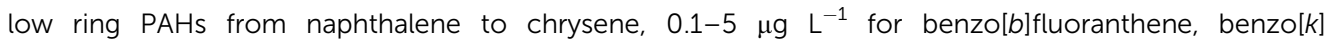
fluoranthene and benzo(a)pyrene. The limits of detection (LOD, S/N = 3) of the method were in the range between $0.02-14.3 \mathrm{ng} \mathrm{L^{-1 }}$. The recoveries for PAHs tested in spiked water samples were in the range $75.6-112.4 \%$ with relative standard deviations (RSD) ranging from $0.1-9.5 \%$. Finally, the method was successfully applied for the analysis of real water samples in the search for PAHs.

\section{Introduction}

Polycyclic aromatic hydrocarbons (PAHs) are a class of semivolatile organic compounds with two or more fused aromatic rings. As we know, PAHs are formed by the incomplete combustion of organic matter and generated whenever fossil fuels or vegetation are burned. These environmental pollutants are ubiquitous under the influence of atmospheric circulation and the water cycle, even in the Arctic and Antarctica in which there is almost no human activity. ${ }^{1}$ The NHANES have shown that humans, starting from fetuses, are under the toxic effects of PAHs, which can increase the risk of adverse health effects. ${ }^{2}$ Moreover, DNA adducts in all cell types and carcinogenic PAHs and/or $\mathrm{B}[a] \mathrm{P}$ in the inhaled air showed positive significant correlations $(r=0.38-0.45, P<0.001){ }^{3}$ Hence, the toxicity of PAHs has justified their inclusion in environmental legislation worldwide. For instance, the U.S. Environmental Protection Agency (EPA) developed ambient

${ }^{a}$ State Key Laboratory of Biogeology and Environmental Geology, China University of Geosciences, Wuhan, 430074, PR China.E-mail: shukuizhu@126.com

${ }^{b}$ State Key Laboratory of Isotope Geochemistry, Guangzhou Institute of Geochemistry, Chinese Academy of Sciences, P. O. Box 1131, Wushan, Guangzhou 510640, PR China ${ }^{c}$ Testing \& Technology Centre for Industrial Products, Shenzhen Entry-exit Inspection and Quarantine Bureau, 518067, PR China

$\dagger$ Electronic supplementary information (ESI) available. See DOI: 10.1039/c7ra10551g water quality criteria and gave priority to 16 PAHs in control in 1985.

The relevance of water in environmental research is related to the hydrophobic properties of organic pollutants, referring to the octanol-water partition coefficient, and their exchange between water and particulate phase in water. Particularly, PAHs barely have an affinity for water, resulting in a low pollution concentration, and so sample enrichment is essential before instrument analysis. Meanwhile, more sensitive analytical methods aimed at improving the current ones are required to meet environment quality and eco-toxicological considerations. Traditional methods such as liquid-liquid extraction (LLE) are laborious, time-consuming, uneconomic and solventwasting. ${ }^{4,5}$ In our group, gas purge microsyringe extraction (GPMSE) and micro-solid phase extraction based on a glass pipette have been developed recently and shows some outstanding advantages, but needs to couple other sample pretreatment steps when analyzing water samples. ${ }^{6-9}$

Magnetic solid phase extraction (MSPE), developed from SPE, has drawn great attention for its advantages of extraction efficiency and material reuse. ${ }^{\mathbf{1 0 - 1 4}}$ Magnetic or magnetizable adsorbents can be dispersed in sample matrix for preconcentration of target analytes, and isolated from matrix by using an external magnet. Besides, the magnetic substrates, such as nano-iron oxide, can enhance the extraction efficiency for their large uniform nanometer-scale pore structure, high specific surface area and large pore volume. ${ }^{15-17}$ However, an 
unavoidable problem associated with particles in this size range is their intrinsic instability, which tends to lead to formation of agglomerates. Moreover, naked metallic nanoparticles are easily oxidized in air, which result in loss of magnetism and dispersibility. ${ }^{\mathbf{1 8}}$ Fortunately, the magnetic substrates can be assembled specialized with different functional groups for various analytes and shown positive effect. ${ }^{18-21}$ Furthermore, not only the specific surface area, but the high $\pi$-electron density of adsorptions is important for phenyl adsorbates. ${ }^{22-24}$ For example, although the surface area is only $53.8 \mathrm{~m}^{2} \mathrm{~g}^{-1}$, the adsorption capacity of STY/DVB/GMA polyHIPE monolith is $16.21 \mathrm{mg}$ Ant per $\mathrm{g}$ polyHIPE polymers. ${ }^{24}$ As a single layer $\mathrm{sp}^{2}$ bonded carbon materials with two dimensional lattices, graphene has excellent physico-chemical properties including a remarkably stable structure and properties, large surface area and delocalized $\pi$-electron system. Many studies have shown that graphene can stabilize the dispersion of metals and metal oxides, in which graphene coupled with $\mathrm{Fe}_{3} \mathrm{O}_{4}$ has been widely used in battery, medical imaging and sensors etc. ${ }^{13,25-30}$ There are also applications in analysis of PAHs, ${ }^{30}$ but they were limited to PAHs with low molecular weight. ${ }^{31-33}$

In this study, a novel nanocomposite of reduced graphene oxide $\left(\mathrm{Fe}_{3} \mathrm{O}_{4} / \mathrm{rGO}\right)$ was synthesized as an adsorbent for MSPE, and coupled with GC-MS for the simultaneous determination of PAHs from low to high molecular weight (2-5 rings). Several parameters affecting the extraction efficiency, such as amount of magnetic graphene, extraction time, the type and volume of desorption solvent, desorption time and organic modifier, were studied in detail. The method showed high sensitivity for analysis of PAHs in real water samples.

\section{Experimental section}

\subsection{Chemicals and materials}

PAHs standards dissolved in binary mixed solvents benzene/ dichloromethane $(1: 1 \mathrm{v} / \mathrm{v})$ were purchased from ANPEL Laboratory Technologies Inc. (Shanghai, China), including naphthalene (Nap), acenaphthylene (Acp), acenaphthene (Ace), fluorene (Flu), phenanthrene (Phe), anthracene (Ant), fluoranthene (Flt), pyrene (Pyr), benz $[a]$ anthracene $(\mathrm{BaA})$, chrysene (Cry), benzo[b]fluoranthene (BbF), benzo[k]fluoranthene (BkF) and benzo[a]pyrene (BaP). The concentration of each compound in the mixture was $2000 \mathrm{mg} \mathrm{\textrm {L } ^ { - 1 }}$. HPLC-grade toluene and $n$-hexane were purchased from Tedia Company (Fairfield, OH, USA), methanol was purchased from Merck Kgaa (Darmstadt, Germany) and acetone was purchased from Mreda Technology Inc. (USA). Graphite was purchased from Aladdin (Shanghai, China), analytical-grade 2-propanol, ethylene glycol, concentrated sulfuric acid $\left(\mathrm{H}_{2} \mathrm{SO}_{4}\right)$, hydrochloric acid $(\mathrm{HCl})$, potassium thiosulfate $\left(\mathrm{K}_{2} \mathrm{~S}_{2} \mathrm{O}_{4}\right)$, phosphorus pentoxide $\left(\mathrm{P}_{2} \mathrm{O}_{5}\right)$, potassium permanganate $\left(\mathrm{KMnO}_{4}\right)$, ferric trichloride hexahydrate $\left(\mathrm{FeCl}_{3} \cdot 6 \mathrm{H}_{2} \mathrm{O}\right)$, sodium acetate $(\mathrm{NaAc})$ and ascorbic acid (VC) were purchased from Sinopharm Chemical Reagents Co., Ltd (Shanghai, China). The ultrapure water was obtained from a Smart-N (Heal Force NW, China) water purification system.

\subsection{Sample preparation}

A stock solution (containing $5 \mathrm{mg} \mathrm{L}^{-1}$ of each analyte) was prepared by diluting the standard PAHs solution with methanol and was stored at $4{ }^{\circ} \mathrm{C}$ in the refrigerator. Working solutions were prepared daily by appropriate dilution of the stock solution with ultrapure water before use.

Real water samples, including drinking water and river water, were collected from commercially mineral water and Hanjiang River, which is the branch of Yangtze River. The river water sample was filtered through a $0.45 \mu \mathrm{m}$ membrane to eliminate particulate matters and stored in brown glass bottles before analysis.

\subsection{Preparation of $\mathrm{Fe}_{3} \mathrm{O}_{4} / \mathrm{rGO}$ and MSPE procedure}

The synthetic routes for $\mathrm{Fe}_{3} \mathrm{O}_{4} / \mathrm{rGO}$ and MSPE procedure are illustrated in Scheme 1. GO was synthesized from natural graphite based on the modified Hummers method, which is widely used to prepared GO. ${ }^{25,31}$ The GO colloid was prepared through two stages. The first stage was a modest and slow prooxide process as follows: $3.0 \mathrm{~g}$ of natural graphite, $2.5 \mathrm{~g}$ of $\mathrm{K}_{2} \mathrm{~S}_{2} \mathrm{O}_{4}$ and $2.5 \mathrm{~g}$ of $\mathrm{P}_{2} \mathrm{O}_{5}$ were added into $15 \mathrm{~mL}$ of concentrated $\mathrm{H}_{2} \mathrm{SO}_{4}$. With vigorous stirring, the temperature of the mixture was maintained at $80^{\circ} \mathrm{C}$ for $6 \mathrm{~h}$.

The resulting suspension could not be filtered until it was cooled and thoroughly precipitated. The solid mixture was washed with ultrapure water and dried at $60{ }^{\circ} \mathrm{C}$ under vacuum as pre-oxidation product. The second stage was a further oxide process. Briefly, $0.6 \mathrm{~g}$ of pre-oxidation product was added into $21.8 \mathrm{~mL}$ of concentrated $\mathrm{H}_{2} \mathrm{SO}_{4}$. With vigorous stirring, $3 \mathrm{~g}$ of $\mathrm{KMnO}_{4}$ was gradually added, and the temperature of the mixture was controlled under $5{ }^{\circ} \mathrm{C}$ for $1 \mathrm{~h}$. The ice bath was then removed, and the temperature of the mixture was maintained at $35^{\circ} \mathrm{C}$ for $2 \mathrm{~h}$. Next, $45 \mathrm{~mL}$ of ultrapure water was slowly added into the mixture in ice bath to prevent the temperature rising violently. The temperature of the mixture was maintained at $35{ }^{\circ} \mathrm{C}$ for $2 \mathrm{~h}$ once again. Then vast water was used to terminate reaction, and shortly, $4 \mathrm{~mL}$ of $30 \% \mathrm{H}_{2} \mathrm{O}_{2}$ aqueous solution were added with stirring. The resulting suspension was filtered and washed with dilute $\mathrm{HCl}$ aqueous solution under the filter as well as with ultrapure water under centrifuge. Finally, the resulting solution was dried naturally and the khaki GO product was obtained.

$\mathrm{Fe}_{3} \mathrm{O}_{4} / \mathrm{rGO}$ was synthesized by the in-site solvothermal method in the presence of graphene. ${ }^{34}$ Firstly, a stably dispersed

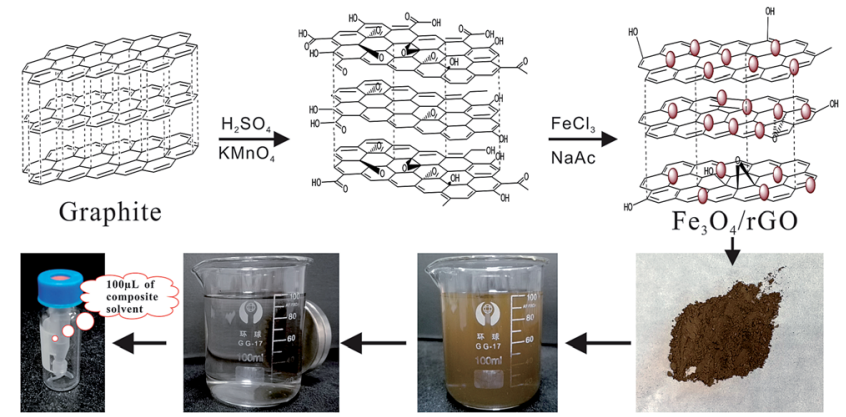

Scheme 1 Schematic of the synthesis of $\mathrm{Fe}_{3} \mathrm{O}_{4} / \mathrm{rGO}$ and MSPE procedure for analysis of PAHs in water. 
graphite oxide ethylene glycol solution was prepared by exfoliation of $75 \mathrm{mg}$ of graphite oxide via ultrasonication for $2 \mathrm{~h}$. Secondly, $10 \mathrm{mg}$ of VC was added in the solution, and kept it under ultrasonic field for $1 \mathrm{~h}$ to reduce the GO initially. Thirdly, $1.35 \mathrm{~g}$ of $\mathrm{FeCl}_{3} \cdot 6 \mathrm{H}_{2} \mathrm{O}$ and $3.6 \mathrm{~g}$ of $\mathrm{NaAc}$ were added and a uniform solution was formed. Then transmit the solution to Teflon-lined stainless steel autoclave and heat at $180{ }^{\circ} \mathrm{C}$ for $8 \mathrm{~h}$. Finally, the precipitate was alternately washed with water and ethanol for final cleaning. The product $\mathrm{Fe}_{3} \mathrm{O}_{4} / \mathrm{rGO}$ was obtained after drying at $50{ }^{\circ} \mathrm{C}$ under vacuum for $24 \mathrm{~h}$.

$10 \mathrm{mg}$ of $\mathrm{Fe}_{3} \mathrm{O}_{4} / \mathrm{rGO}$ was dispersed into $100 \mathrm{~mL}$ of aqueous sample under ultrasound for $8 \mathrm{~min}$ for extraction. Then, the $\mathrm{NdFeB}$ magnet was held at the bottom of the flask and the $\mathrm{Fe}_{3} \mathrm{O}_{4} / \mathrm{rGO}$ adsorbent was isolated from the suspension. After $10 \mathrm{~min}$, the suspension became clear and then was decanted. The residual adsorbent was transmitted into a $5 \mathrm{~mL}$ vial, washed with ultrapure water and dried under a mild stream of nitrogen. Then it was eluted with $100 \mu \mathrm{L}$ of binary mixed solvents of toluene and acetone $(3: 1 \mathrm{v} / \mathrm{v})$ under water bath at $50{ }^{\circ} \mathrm{C}$ for $5 \mathrm{~min}$. After cooling to room temperature, $1.0 \mu \mathrm{L}$ of the final extract is injected in the GC/MS system for analysis.

\subsection{Instrumentation and methods}

Powder X-ray diffraction (XRD) patterns of materials were obtained with a diffractometer (Rigaku D/max- $\beta$ B) using $\mathrm{Cu} \mathrm{K} \alpha$ radiation source. The microcrystalline structure and surface characteristics of the samples were characterized by using Hitachi S-4800 scanning electron microscopy (SEM). Fourier transform infrared (FTIR) spectra were obtained with a Bruker Equinox 55 FT-IR instrument.
GC-MS analysis was performed on a 7890A GC interfaced to 5975C mass spectrometer system (Agilent Technologies, USA). The GC separation was equipped with a DB-5MS column $(30 \mathrm{~m}$ $\times 0.25 \mathrm{~mm} \times 0.25 \mu \mathrm{m}$, Agilent Technologies, USA). Helium (purity 99.999\%) was employed as the carrier gas at a flow rate of

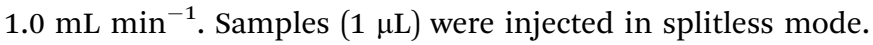
The injector temperature was set at $300{ }^{\circ} \mathrm{C}$. The GC oven was initially held at $40^{\circ} \mathrm{C}$ for $1 \mathrm{~min}$ and then programmed to $300{ }^{\circ} \mathrm{C}$ at $7{ }^{\circ} \mathrm{C} \mathrm{min}^{-1}$ and held for $5 \mathrm{~min}$. The solvent delay time was $10 \mathrm{~min}$. PAHs standards and samples were analyzed in selective ion monitoring (SIM) mode for quantitative determination of the analytes. The masses monitored by the detector were set as follows: $10-15 \mathrm{~min}, \mathrm{~m} / \mathrm{z} 128,129,127,102$; 15-20 $\mathrm{min}, \mathrm{m} / \mathrm{z} 152$, $153,151,154 ; 20-22 \mathrm{~min}, \mathrm{~m} / \mathrm{z} 166,165,167,139 ; 22-26 \mathrm{~min}, \mathrm{~m} / \mathrm{z}$ $178,176,179,152 ; 26-30 \mathrm{~min}, \mathrm{~m} / z$ 202, 203, 200, 101; 30$35 \mathrm{~min}, \mathrm{~m} / \mathrm{z} 228,226,229,227,252 ; 35-43 \mathrm{~min}, \mathrm{~m} / \mathrm{z} 253,252$, 250, 126. PAHs standards and samples were analyzed in SIM mode for quantitative determination of the analytes: Nap, $\mathrm{m} / \mathrm{z}$ 128, 129, 127, 102; Acp, $m / z$ 152, 153, 151; Ace, 153, 154, 152; Flu, $m / z$ 166, 165, 167; Phe, $m / z$ 178, 176, 179; Ant, $m / z$ 178, 179 , 176; Flt, $m / z$ 202, 203, 200, 101; Pyr, $m / z$ 202, 200, 203, 101; Cry, $m / z$ 228, 226, 229; BaA, $m / z$ 228, 226, 227, 229, 252; BbF, $m / z 252$, 253, 250; BkF, $m / z$ 252, 250, 126; BaP, $m / z$ 252, 253, 250, 126.

\section{Results and discussion}

\subsection{Characterization of $\mathrm{Fe}_{3} \mathrm{O}_{4} / \mathrm{rGO}$ nanoparticles}

The structures of $\mathrm{Fe}_{3} \mathrm{O}_{4} / \mathrm{rGO}$ nanoparticles were analysed by FTIR, Raman, XRD and SEM. Fig. 1A is FTIR image of GO, $\mathrm{Fe}_{3} \mathrm{O}_{4}$ and $\mathrm{Fe}_{3} \mathrm{O}_{4} / \mathrm{rGO}$, which showed the changes of group functions
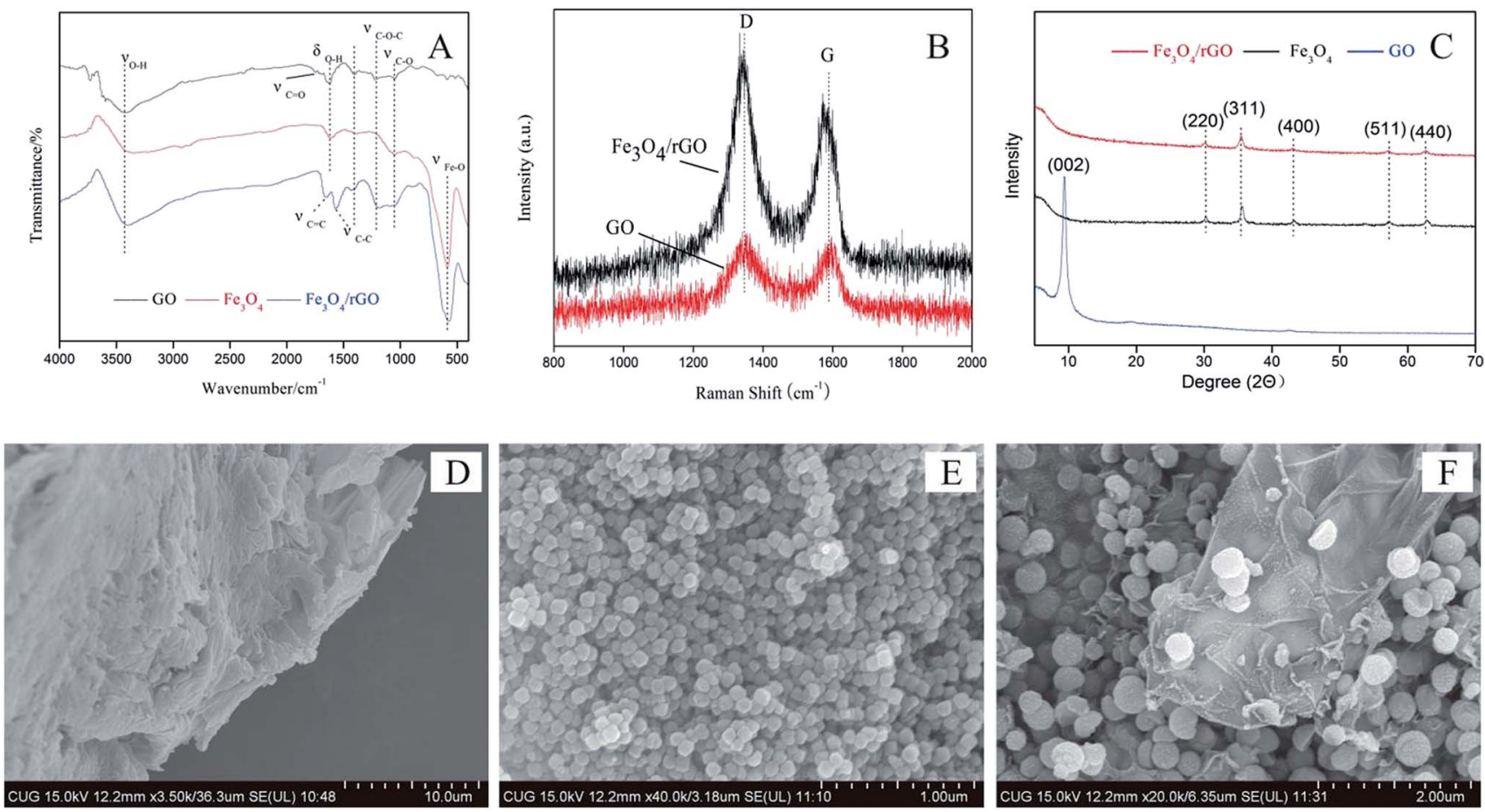

Fig. 1 (A) FTIR spectra of $\mathrm{GO}, \mathrm{Fe}_{3} \mathrm{O}_{4}$ and $\mathrm{Fe}_{3} \mathrm{O}_{4} / \mathrm{rGO}$; (B) Raman spectra of $\mathrm{Fe}_{3} \mathrm{O}_{4} / \mathrm{rGO}$ and $\mathrm{GO}$; (C) X-ray diffraction patterns of $\mathrm{GO}$, Fe $3 \mathrm{O}_{4}$ and $\mathrm{Fe}_{3} \mathrm{O}_{4} / \mathrm{rGO}$; SEM images of (D) GO, (E) $\mathrm{Fe}_{3} \mathrm{O}_{4}$ and (F) $\mathrm{Fe}_{3} \mathrm{O}_{4} / \mathrm{rGO}$. 
accompanying with the synthesis of $\mathrm{Fe}_{3} \mathrm{O}_{4} / \mathrm{rGO}$. It can be seen from the FTIR image of pristine GO that the signals of four groups of obvious transmission peak at $3430 \mathrm{~cm}^{-1}(\mathrm{O}-\mathrm{H}$ stretching), $1627 \mathrm{~cm}^{-1}$ (O-H bending vibration), $1220 \mathrm{~cm}^{-1}$ and $1052 \mathrm{~cm}^{-1}$ (C-O stretching), $1700 \mathrm{~cm}^{-1}$ ( $\mathrm{C}=\mathrm{O}$ stretching). Based on the proofs that the $\mathrm{O}-\mathrm{H}$ stretching was much stronger than $\mathrm{C}-\mathrm{O}$ stretching and $\mathrm{C}=\mathrm{O}$ stretching, even the $\mathrm{C}=\mathrm{O}$ stretching was too weak to discern, the modified Hummers method was mild enough to prepare GO with fewer unrecoverable defects to aromatic rings. The functional groups of $\mathrm{Fe}_{3} \mathrm{O}_{4}$ nanoparticles were $\mathrm{Fe}-\mathrm{O}\left(584 \mathrm{~cm}^{-1}\right)$ and $\mathrm{O}-\mathrm{H}\left(3390 \mathrm{~cm}^{-1}\right.$ and $1630 \mathrm{~cm}^{-1}$ ), which was turned out by FTIR image. The spectrum of the $\mathrm{Fe}_{3} \mathrm{O}_{4} / \mathrm{rGO}$ was assumed integrated characteristics similar to that of $\mathrm{Fe}_{3} \mathrm{O}_{4}$ and GO. Thereinto, the intensity of $\mathrm{O}-\mathrm{H}$ stretching vibration $\left(3390 \mathrm{~cm}^{-1}\right)$ increased. These spectral characteristics proved that the combination of $\mathrm{Fe}_{3} \mathrm{O}_{4}$ and GO was successful. It's worth noting that the bands attributed to the $\mathrm{C}-\mathrm{O}$ stretching $\left(1220 \mathrm{~cm}^{-1}\right.$ and $\left.1052 \mathrm{~cm}^{-1}\right)$ strengthened, and $\mathrm{C}=\mathrm{C}$ stretching $\left(1660 \mathrm{~cm}^{-1}\right), \mathrm{C}-\mathrm{C}$ stretching in benzene rings $\left(1600 \mathrm{~cm}^{-1}, 1580 \mathrm{~cm}^{-1}\right.$ and $\left.1440 \mathrm{~cm}^{-1}\right)$ appeared. The FTIR results thus demonstrated that the $\mathrm{GO}$ was successfully reduced with $\mathrm{VC}$ and functionalized with $\mathrm{Fe}_{3} \mathrm{O}_{4}$.

The Raman spectra of graphite is very sensitive to the structural changes during the chemical reactions. ${ }^{35}$ It is stated that the spectra of graphite with high crystallinity has two sharp band at $1580 \mathrm{~cm}^{-1}$ (G band) and $1350 \mathrm{~cm}^{-1}$ (D band), respectively. ${ }^{36}$ The intensity ratio of the $\mathrm{D}$ and $\mathrm{G}$ band $\left(I_{\mathrm{D}} / I_{\mathrm{G}}\right)$ is a useful indicator to evaluate the ordered and disordered crystal structures of carbon, and the larger the $I_{\mathrm{D}} / I_{\mathrm{G}}$ ratio, the higher the defect density. ${ }^{36,37}$ The value of ID/IG is 0.34 for graphite, and it increases to 1.99 for GO (Fig. 1B), indicating the introduction of many defect sites to GO by the oxidative treatment of graphite. As a comparison, The $I_{\mathrm{D}} / I_{\mathrm{G}}$ for $\mathrm{Fe}_{3} \mathrm{O}_{4} / \mathrm{rGO}$ reduces to 1.7 , which could be attributed to reduction with ascorbic acid and EDG for solvothermal reduction, and still be larger than graphite, suggesting that $\mathrm{D}$ band is dominated by graphitic carbon.

XRD image indicated that $\mathrm{GO}, \mathrm{Fe}_{3} \mathrm{O}_{4}$ and $\mathrm{Fe}_{3} \mathrm{O}_{4} / \mathrm{rGO}$ had integrated structure (Fig. 1C). A sharpen reflection peak at $c a .9 .4^{\circ}$ corresponding to the (002) reflection was examined in GO. The intraplanar lattice spacing was $0.94 \mathrm{~nm}$ calculated by the DebyeScherrer formula, much higher than graphite $(0.34 \mathrm{~nm})$. A number of prominent Bragg reflections at $c a .30 .3^{\circ}, 35.6^{\circ}, 43.2^{\circ}$, $57.3^{\circ}, 62.9^{\circ}$ matched with the standards indices of crystal face of magnetic $\mathrm{Fe}_{3} \mathrm{O}_{4}$, inverse spinel, corresponding to (220), (311), (400), (511) and (440) planes. However, the only special part was that the reflection peak of GO disappeared. It resulted from the low concentration of rGO and the inserting of $\mathrm{Fe}_{3} \mathrm{O}_{4}$ between $\mathrm{rGO}$ layers dispersion of magnetite between layers of graphene, which has been proved by the SEM image (Fig. 1D-F). It can be seen that sheet-like structure was smooth surfaces and crumpled edges in GO, globular clusters had a uniform size in $\mathrm{Fe}_{3} \mathrm{O}_{4}$ and the magnetite dispersed in interlamination and surface of graphene.

\subsection{Optimization of the extraction parameters}

Hydrophilic-lipophilic balance and binding energy between PAHs and adsorbent are the key factors to affect the ability of extraction and desorption. In order to obtain high extraction efficiency, some parameters including the amount of sorbent material, the extraction time and extraction temperature, the desorption solvent and desorption time, the effect of organic modifier, were evaluated. All the experiments were performed using $5 \mu \mathrm{g} \mathrm{L} \mathrm{L}^{-1}$ of PAHs aqueous samples by mixing an appropriate amount of the stock solution with ultrapure water. The detailed extraction conditions in the following experiments were shown in (ESI $\dagger$ ).

In order to choose the optimum dosage of the adsorbent $\left(\mathrm{Fe}_{3} \mathrm{O}_{4} / \mathrm{rGO}\right)$ for the adsorption of the PAHs, different amounts of the $\mathrm{Fe}_{3} \mathrm{O}_{4} / \mathrm{rGO}$ were investigated in the range from 3.0 to $15.0 \mathrm{mg}$. Fig. $2 \mathrm{~A}$ indicated that the peak areas increased for $2-3$
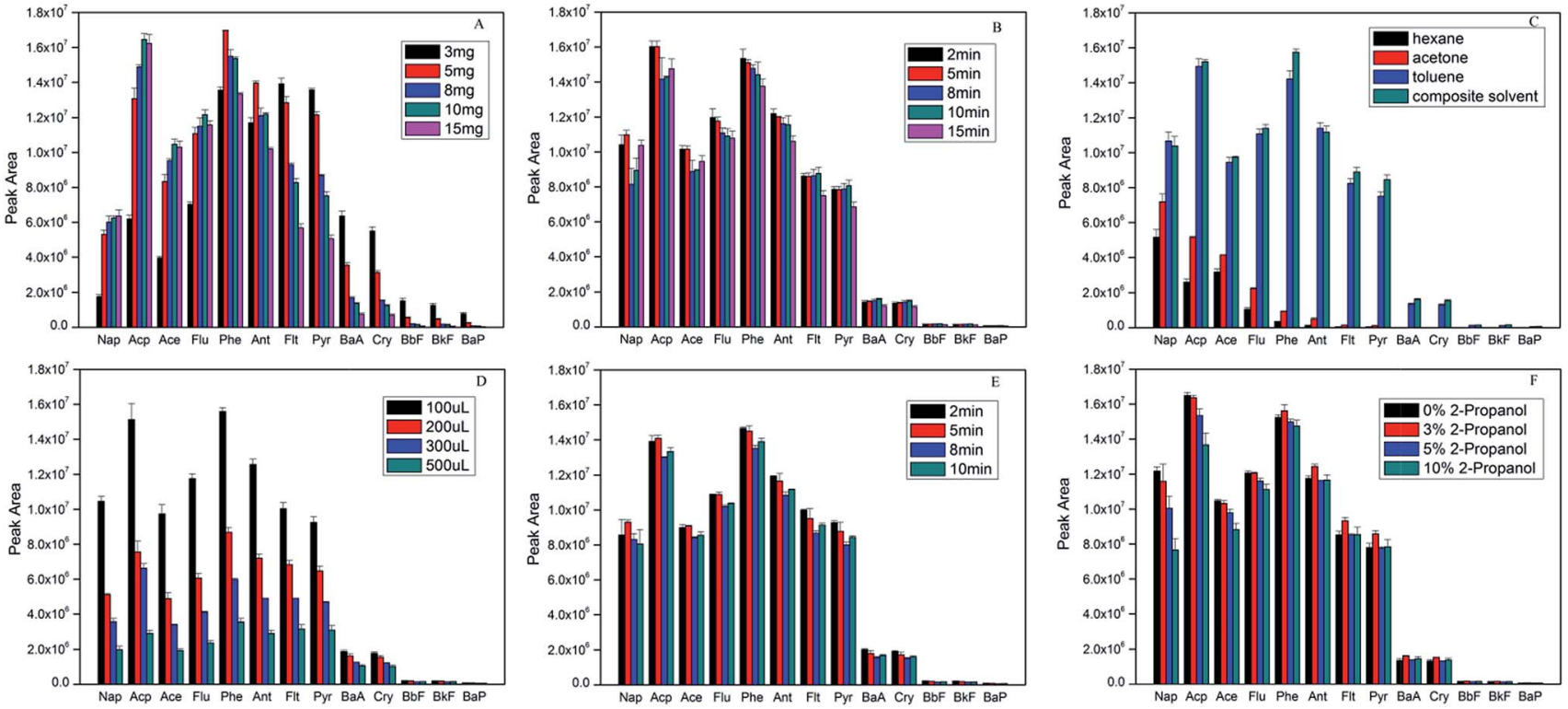

Fig. 2 Effect of (A) sorbent amount, (B) extraction time, (C) desorption solvent type, (D) desorption solvent amount, (E) desorption time and (F) organic modifier on extraction efficiency. 
rings PAHs with increasing sorbent material, while high ring PAHs decreased. When the amount of adsorbent materials was more than $10 \mathrm{mg}$, the test signal of PAHs was not improved. On the contrary, the peak area of most PAHs decreased, especially 4-5 rings PAHs. It is considered that more rings for PAHs could achieve stronger $\pi-\pi$ conjugation with rGO, to the extent, were more difficult to elute with more sorbents. ${ }^{16,38}$ On all account, $10 \mathrm{mg}$ of $\mathrm{Fe}_{3} \mathrm{O}_{4} / \mathrm{rGO}$ was chosen for optimal dosage in optimization experiments.

Generally, adsorption and desorption happen simultaneously during the process of extraction. The extracting efficiency will increase until adsorption and desorption come to dynamic balance. In this study, the effect of the extraction time was investigated in the range of 2 to $15 \mathrm{~min}$. Fig. 2B showed the extraction time profile. Once the materials were dispersed evenly, the signals were almost of no differences even with more extraction time than $5 \mathrm{~min}$. However, the peak areas decreased little by little after $8 \mathrm{~min}$. It is believed that ultrasonic may strengthen the back-diffusion of analytes, which frequently occurred in many microextraction procedures. ${ }^{33}$

Desorption capabilities of solvents were assessed with four solvents including $n$-hexane, toluene, acetone and a binary mixed solvents of toluene and acetone (3:1 v/v). Fig. $2 \mathrm{C}$ showed the results of the comparative studies. It was observed that composite solvent gave the highest chromatographic response, followed by toluene, acetone and $n$-hexane. Taken into consideration that hexane and acetone have the strongest hydrophobicity and polarity respectively, the strong van der Waals interaction between the analytes and benzene rings might be responsible for this observation. In addition, the interaction in a model complex of HCHO-benzene is much stronger (1.87 kcal $\left.\mathrm{mol}^{-1}\right)$ than a $\mathrm{CH}_{4}$-benzene interaction $\left(0.53 \mathrm{kcal} \mathrm{mol}^{-1}\right) .{ }^{39}$ Obviously, composite solvent as desorption solvent for PAHs analysis in this current method was borne out by the experimental observations.

The volume of desorption solvent and desorption time are vital for the desorption efficiency. Fig. 2D showed the influence of the volume of desorption solvent evaluated ranging from 100 $\mu \mathrm{L}$ to $500 \mu \mathrm{L}$. It could be seen that the smaller the volume of binary mixed solvents was used, the higher concentration of PAHs can be obtained in the desorption solution. Therefore, $100 \mu \mathrm{L}$ of composite solvent was adopted in this study.

Moreover, desorption time was also studied from 2 to $10 \mathrm{~min}$ (shown in Fig. 2E). The peak areas of analytes did not significantly increase for most PAHs with more desorption time. At the same time, all signals slightly decreased after $5 \mathrm{~min}$ for desorption. All things considered, $5 \mathrm{~min}$ is a reasonable compromise.

Organic modifier was studied to evaluate whether PAHs can adsorb onto the surfaces of containers or not. ${ }^{\mathbf{1 , 4 0 , 4 1}}$ Fig. $2 \mathrm{~F}$ showed the results of adding different percentages of 2-propanol to the sample solution. The results demonstrated that the peak areas of 2-3 rings of PAHs hardly changed while those of high ring PAHs significantly increased with 3\% 2-propanol. On the other hand, the peak areas for all PAHs decreased when adding 2-propanol more than 3\%. It can be explained that high ring PAHs was more hydrophobic so that they were easier to be adsorbed onto the surfaces of containers. ${ }^{33}$ However, the excessive 2-propanol could probably lead up to the increase of PAHs solubility in the solvent that ironically reduced their availability to the extraction device. ${ }^{\mathbf{1 , 4 0}}$

On the basis of the foregoing discussion, the optimal extraction conditions were as follows: $10 \mathrm{mg}$ of $\mathrm{Fe}_{3} \mathrm{O}_{4} / \mathrm{rGO}$ per $100 \mathrm{~mL}$ solution, sample solution containing 3\% 2-propanol (v/ v), 5 min extraction time, $100 \mu \mathrm{L}$ of binary mixed solvents (toluene : acetone $=3: 1, \mathrm{v} / \mathrm{v}$ ) as the desorption solution, $5 \mathrm{~min}$ desorption time. All the following experiments were carried out under these optimal conditions.

\subsection{Method validation}

Under the optimal extraction conditions mentioned above, proposal method was estimated and validated. Using spiked ultrapure water samples, the factors that affect the analytical performance, such as linearity $\left(R^{2}\right)$, linear range, limits of detection (LODs) were investigated. The analytical results were listed in Table 1 and the GC/MS-SIM chromatogram of PAHs spiked at $5 \mu \mathrm{g} \mathrm{L}^{-1}$ was shown in Fig. 3.

The linearity was studied using ultrapure water samples spiked with PAHs at a series of concentration. The curves of different ring PAHs were linear in the concentration range of

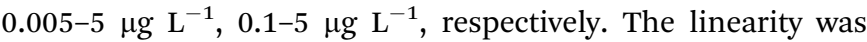
assessed by correlation coefficients $\left(R^{2}\right)$, and were higher than 0.99 for most PAHs. The LODs calculated based on $\mathrm{S} / \mathrm{N}$ of 3 , ranged from 0.02 to $14.3 \mathrm{ng} \mathrm{\textrm {L } ^ { - 1 }}$. The results of RSD were calculated by adopting five replicate runs in the range of 2.5$8.4 \%$.

Moreover, five kinds of different methods used for the study of polycyclic aromatic hydrocarbons, containing SPE, $\mu$-SPE, SPME, IT-SPME, MSPE, were summarized..$^{\mathbf{2 , 3 1 , 3 3 , 4 2 - 4 4}}$ Table 2 summarized the method of specific information, such as sorbents, material dosage, desorption solvents, solvent consumption/sample volume, test number of PAHs, LODs and instrumentation. Compared with SPE and SPME, MSPE showed

Table 1 Analytical parameters of MSPE for determination of PAHs ${ }^{a}$

\begin{tabular}{lllll}
\hline Analytes & $\begin{array}{l}\text { Linear range } \\
\left(\mu \mathrm{g} \mathrm{L}^{-1}\right)\end{array}$ & $\begin{array}{l}\text { Correlation } \\
\text { coefficient }\left(R^{2}\right)\end{array}$ & $\begin{array}{l}\text { LOD } \\
\left(\mathrm{ng} \mathrm{L}^{-1}\right)\end{array}$ & $\begin{array}{l}\text { RSD (\%) } \\
n=5\end{array}$ \\
\hline Nap & $0.005-5$ & 0.9977 & 0.25 & 3 \\
Acp & $0.005-5$ & 0.9998 & 0.15 & 2.6 \\
Ace & $0.005-5$ & 0.9993 & 0.1 & 2.5 \\
Flu & $0.005-5$ & 1 & 0.02 & 2.9 \\
Phe & $0.005-5$ & 1 & 0.02 & 2.7 \\
Ant & $0.005-5$ & 0.9973 & 0.03 & 3.9 \\
Flt & $0.005-5$ & 0.9964 & 0.15 & 5.4 \\
Pyr & $0.005-5$ & 0.9963 & 0.12 & 8.4 \\
Cry & $0.005-5$ & 0.982 & 0.42 & 7.2 \\
BaA & $0.005-5$ & 0.984 & 0.38 & 6.8 \\
BbF & $0.1-5$ & 0.978 & 5 & 5.9 \\
BkF & $0.1-5$ & 0.977 & 5.1 & 5.7 \\
BaP & $0.1-5$ & 0.978 & 14.3 & 6.4 \\
a Results & obtained from & the analysis of & samples & spiked at \\
a concentration of 5 fg L ${ }^{-1}$. & & &
\end{tabular}




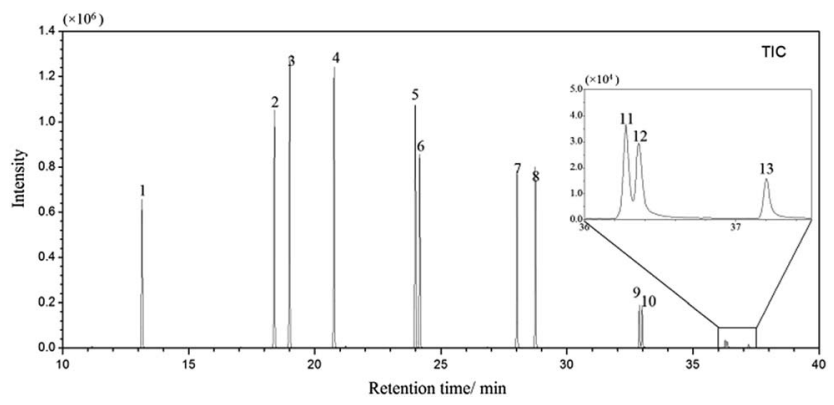

Fig. $3 \mathrm{GC} / \mathrm{MS}$-SIM chromatogram of PAHs in river water sample spiked with standards at $5 \mu \mathrm{g} \mathrm{L}^{-1}$ after MSPE. Sample volume, $100 \mathrm{~mL}$; peak identities: (1) Nap, (2) Acp, (3) Ace, (4) Flu, (5) Phe, (6) Ant, (7) Flt, (8) Pyr, (9) Cry, (10) BaA, (11) BbF, (12) BkF, (13) BaP.

a merit in material dosage, volume of desorption solvent and stability. Previous studies based on MSPE focused on lower ring PAHs, but failed in the analysis of high PAHs. The present method shows an extremely good analytical performance, especially for high ring PAHs.

\subsection{Analysis of real water samples}

In order to further evaluate the application of method, two real water samples were analyzed. All samples obtained were analyzed in three replicates. The results were illustrated in Table 3. There were no PAHs found in drinking water, and trace amount of low ring PAHs were detected in river water, which was probably due to rain leaching into the Hanjiang River. To evaluate the accuracy of the method, the relevant recoveries were analyzed by spiking with PAHs into real water samples at a series of concentrations from $50 \mathrm{ng} \mathrm{L}^{-1}$ to $2.5 \mu \mathrm{g} \mathrm{L}^{-1}$. It can be observed that satisfactory recoveries were obtained ranging from $75.6 \%$ to $112.4 \%$. It suggested that the developed method was suitable for the analysis of environmental water samples in the search for PAHs.

Table 2 Comparison of analysis ability, solvent consumption and precision among different methods

\begin{tabular}{|c|c|c|c|c|c|c|c|c|}
\hline MSPE & $\mathrm{Fe}_{3} \mathrm{O}_{4} @ \mathrm{SiO}_{2}-\mathrm{G}$ & HPLC-FLD & $0.5-5.0$ & Acetone & 15 & $0.3 / 250$ & 5 & 28 \\
\hline IT-SPME & TRB-5 & HPLC-FLD & $2.3-28$ & Acetonitrile & Not reported & $2 / 5$ & 15 & 37 \\
\hline SPE & $\begin{array}{l}\text { Cyclodextrin-silica } \\
\text { microporous composite }\end{array}$ & HPLC-FLD & $50-800$ & Hexane + methanol & 200 & $8 / 100$ & 6 & 38 \\
\hline SPE & Sulfur microparticles & HPLC-UV & $7-48$ & Acetonitrile & 1500 & $2 / 100$ & 10 & 39 \\
\hline MSPE & $\mathrm{Fe}_{3} \mathrm{O}_{4} / \mathrm{rGO}$ & GC-MS & $0.02-14.3$ & $\begin{array}{l}\text { Toluene/acetone } \\
(3: 1, \mathrm{v} / \mathrm{v})\end{array}$ & 10 & $0.1 / 100$ & 13 & This work \\
\hline
\end{tabular}

Table 3 PAHs in real water samples determined by the proposed method

\begin{tabular}{|c|c|c|c|c|c|c|c|c|}
\hline \multirow[b]{2}{*}{ Analytes } & \multicolumn{4}{|l|}{ Drinking water } & \multicolumn{4}{|l|}{ Hanjing river } \\
\hline & $\begin{array}{l}\text { Concentration } \\
\left(\text { ng L }^{-1}\right)(\mathrm{RSD}, n=3)\end{array}$ & $\begin{array}{l}\text { Recovery } \\
(\mathrm{RSD})^{a}\end{array}$ & $\begin{array}{l}\text { Recovery } \\
(\mathrm{RSD})^{b}\end{array}$ & $\begin{array}{l}\text { Recovery } \\
\text { (RSD) }^{c}\end{array}$ & $\begin{array}{l}\text { Concentration } \\
\left(\mathrm{ng} \mathrm{L}^{-1}\right) \\
(\mathrm{RSD}, n=3)\end{array}$ & $\begin{array}{l}\text { Recovery } \\
(\mathrm{RSD})^{a}\end{array}$ & 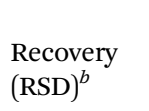 & $\begin{array}{l}\text { Recovery } \\
(\mathrm{RSD})^{c}\end{array}$ \\
\hline Nap & - & $101.6(5.5)$ & $104.4(5.6)$ & $84.4(1.7)$ & 15 & $98.3(7.9)$ & $105.8(3.5)$ & $88.1(1.2)$ \\
\hline Acp & - & $99.8(6.8)$ & $95.2(6.0)$ & $95.0(6.1)$ & - & $98.0(4.1)$ & $84.4(2.1)$ & $92.2(0.1)$ \\
\hline Ace & - & $91.0(7.5)$ & $93.7(7.1)$ & $108.9(6.3)$ & - & $92.0(4.1)$ & $108.0(2.3)$ & $103.2(0.5)$ \\
\hline Flu & - & $100.0(6.5)$ & $100.5(5.7)$ & $106.8(4.4)$ & - & $103.3(2.5)$ & $93.9(2.4)$ & $99.7(0.5)$ \\
\hline Phe & - & $105.0(5.4)$ & $99.9(3.9)$ & $99.5(3.9)$ & - & $93.1(0.6)$ & $98.3(3.5)$ & $109.4(0.8)$ \\
\hline Ant & - & $106.9(0.3)$ & $89.3(5.6)$ & $98.4(3.5)$ & - & $110.6(1.8)$ & $81.6(4.6)$ & $95.4(1.9)$ \\
\hline Flt & - & $98.3(1.1)$ & $83.7(1.3)$ & $92.9(6.1)$ & - & $90.4(6.6)$ & $88.2(8.6)$ & $93.7(3.1)$ \\
\hline Pyr & - & $84.4(2.6)$ & $87.7(2.7)$ & $93.8(6.7)$ & - & $84.1(6.6)$ & $86.4(8.8)$ & $86.9(3.1)$ \\
\hline Cry & - & $96.9(9.5)$ & $108.2(7.0)$ & $86.9(5.1)$ & - & $76.4(2.1)$ & $104.8(9.2)$ & $75.6(1.4)$ \\
\hline $\mathrm{BaA}$ & - & $89.1(5.3)$ & $98.7(7.8)$ & $82.2(6.6)$ & - & $78.0(1.6)$ & $103.1(7.9)$ & $77.3(0.5)$ \\
\hline $\mathrm{BbF}$ & - & - & $112.4(3.2)$ & $91.7(3.1)$ & - & - & $96.9(7.5)$ & $92.5(2.3)$ \\
\hline $\mathrm{BkF}$ & - & - & $109.4(7.5)$ & $101.7(1.9)$ & - & - & $102.7(7.8)$ & $110.9(1.2)$ \\
\hline $\mathrm{BaP}$ & - & - & $83.0(9.2)$ & $88.2(7.1)$ & - & - & $83.0(3.4)$ & $97.1(3.7)$ \\
\hline
\end{tabular}

${ }^{a}$ Spiked at a concentration of $50 \mathrm{ng} \mathrm{L}^{-1} \cdot{ }^{b}$ Spiked at a concentration of $250 \mathrm{ng} \mathrm{L}{ }^{-1}$. ${ }^{c}$ Spiked at a concentration of $2.5 \mu \mathrm{g} \mathrm{L}{ }^{-1}$; - non-detected or below LOD. 


\section{Conclusions}

In the present study, an extraction method suitable for the simultaneous determination of PAHs from low to high molecular weight (2-5 rings) in water was developed based on a magnetic nanocomposite of reduced graphene oxide $\left(\mathrm{Fe}_{3} \mathrm{O}_{4} /\right.$ rGO). By comparing elution of PAHs using various solvents with different polarity, hydrophobic property and characteristic functional groups, a conclusion had been drawn that effect of elution was mainly associated with the polarity and functional groups of the solvents. Phenyl in toluene and carbonyl in acetone increase the extraction efficiency due to $\pi-\pi$ interactions and $\mathrm{p}-\pi$ interactions, respectively. In addition, only 100 $\mu \mathrm{L}$ of binary mixed solvents could effectively desorb PAHs on the surface of magnetic materials. The decrease of organic solvent is influential, not only for researcher's health and economy, but also reducing the damage to the environment and conforming to trend of environment-friendly technologies. Conceivably, the procedure provided a simple, sensitive and efficient method for the simultaneous determination of diverse PAHs in environmental water samples.

\section{Conflicts of interest}

There are no conflicts to declare.

\section{Acknowledgements}

The authors are grateful for financial support from the National Natural Science Foundation of China (No. 21077039, 41603045) and the Programme of Introducing Talents of Discipline to Universities (No. B14031).

\section{References}

1 L. Guo and H. K. Lee, J. Chromatogr. A, 2011, 1218, 93219327.

2 T. J. Woodruff, A. R. Zota and J. M. Schwartz, Environ. Health Perspect., 2011, 119, 878-885.

3 B. Binková, J. Topinka, G. Mracková, D. Gajdosová, P. N. Vidová, Z. Stávková, V. T. Peterka, T. Pilcík, V. R. Rimár, L. R. Dobiás, P. B. Farmer and R. J. Rám, Mutat. Res., Genet. Toxicol. Environ. Mutagen., 1998, 416, 67-84.

4 Z. Li, L. C. Romanoff, D. A. Trinidad, N. Hussain, R. S. Jones, E. N. Porter, D. G. Patterson and A. Sjodin, Anal. Chem., 2006, 78, 5744-5751.

5 R. Fan, R. Ramage, D. Wang, J. Zhou and J. She, Talanta, 2012, 93, 383-391.

6 X. Gao, S. Zhu, W. Zhang, D. Li, W. Dai and S. He, Fuel, 2016, 182, 788-797.

7 X. Gao, L. Pang, S. Zhu, W. Zhang, W. Dai, D. Li and S. He, Org. Geochem., 2017, 106, 30-47.

8 W. Zhang, S. Zhu, L. Pang, X. Gao, G. Zhu and D. Li, J. Chromatogr. A, 2016, 1478, 75-83.

9 G. Zhu, S. He, X. He, S. Zhu and Y. Feng, RSC Adv., 2017, 7, 40608-40614.
10 S. Zhang, H. Niu, Y. Cai and Y. Shi, Anal. Chim. Acta, 2010, 665, 167-175.

11 Q. Zhao, F. Wei, Y. Luo, J. Ding, N. Xiao and Y. Feng, J. Agric. Food Chem., 2011, 59, 12794-12800.

12 S. Huo and X. Yan, Analyst, 2012, 137, 3445-3451.

13 G. Giakisikli and A. N. Anthemidis, Anal. Chim. Acta, 2013, 789, 1-16.

14 M. Wierucka and M. Biziuk, TrAC, Trends Anal. Chem., 2014, 59, 50-58.

15 S. Sadeghi, H. Azhdari, H. Arabi and A. Z. Moghaddam, J. Hazard. Mater., 2012, 215-216, 208-216.

16 Q. Zhao, F. Wei, N. Xiao, Q. Yu, B. Yuan and Y. Feng, J. Chromatogr. A, 2012, 1240, 45-51.

17 M. Ghaedi, S. Hajjati, Z. Mahmudi, I. Tyagi, S. Agarwal, A. Maity and V. K. Gupta, Chem. Eng. J., 2015, 268, 28-37.

18 L. Xie, R. Jiang, F. Zhu, H. Liu and G. Ouyang, Anal. Bioanal. Chem., 2014, 406, 377-399.

19 C. Chen, Y. Yu, W. Li, C. Cao, P. Li, Z. Dou and W. Song, J. Mater. Chem., 2011, 21, 12836-12841.

20 W. Li, D. Chen, F. Xia, J. Tan, P. Huang, W. Song, N. Nursam and R. Caruso, Environ. Sci.: Nano, 2016, 3, 94-106.

21 L. Chen, T. Wang and J. Tong, TrAC, Trends Anal. Chem., 2011, 30, 1095-1108.

22 S. Lamichhane, K. Bal Krishna and R. Sarukkalige, Chemosphere, 2016, 148, 336-353.

23 K. Yuan, J. Wang, H. Zhai, Z. Chen, L. Huang and Z. Su, Anal. Methods, 2015, 7, 8297-8303.

24 R. Su, G. Ruan, H. Nie, T. Xie, Y. Zheng, F. Du and J. Li, J. Chromatogr. A, 2015, 1405, 23-31.

25 J. Gao, F. Liu, Y. Liu, N. Ma, Z. Wang and X. Zhang, Chem. Mater., 2010, 22, 2213-2218.

26 Q. Wu, G. Zhao, C. Feng, C. Wang and Z. Wang, J. Chromatogr. A, 2011, 1218, 7936-7942.

27 X. Cao, J. Chen, X. Ye, F. Zhang, L. Shen and W. Mo, J. Sep. Sci., 2013, 36, 3579-3585.

28 B. Zawisza, R. Sitko, E. Malicka and E. Talik, Anal. Methods, 2013, 5, 6425-6430.

29 Y. Zhao, X. Li, X. Zhou and Y. Zhang, Sens. Actuators, B, 2013, 231, 324-340.

30 R. Sitko, B. Zawisza and E. Malicka, TrAC, Trends Anal. Chem., 2013, 51, 33-43.

31 W. Wang, R. Ma, Q. Wu, C. Wang and Z. Wang, J. Chromatogr. A, 2013, 1293, 20-27.

32 J. Wang, Z. Chen and B. Chen, Environ. Sci. Technol., 2014, 48, 4817-4825.

33 N. N. Naing, S. F. Yau Li and H. K. Lee, J. Chromatogr. A, 2016, 1440, 23-30.

$34 \mathrm{H}$. Bagheri, A. Afkhami, P. Hashemi and M. Ghanei, RSC Adv. , 2015, 5, 21659.

35 L. Zhang, W. Li, Z. Cui and W. Song, J. Phys. Chem. C, 2009, 113, 20594-20598.

36 H. He and C. Gao, ACS Appl. Mater. Interfaces, 2010, 2, 32013210 .

37 W. Li, L. Zhang, Q. Wang, Y. Yu, Z. Chen, C. Cao and W. Song, J. Mater. Chem., 2012, 22, 15342-15347.

38 J. Ma, R. Xiao, J. Li, J. Yu, Y. Zhang and L. Chen, J. Chromatogr. A, 2010, 1217, 5462-5469. 
39 A. K. Mallik, S. Guragain, H. Hachisako, M. M. Rahman, M. Takafuji and H. Ihara, J. Chromatogr. A, 2014, 1324, 149-154.

40 L. Wolska, M. Rawa-Adkonis and J. Namieśnik, Anal. Bioanal. Chem., 2005, 382, 1389-1397.

41 W. Li, F. Xia, J. Qiu, P. Li, D. Chen, Z. Chen, Y. Yu, Y. Lu, R. Caruso and W. Song, Nano Res., 2014, 7, 903-916.
42 V. Khalili-Fard, K. Ghanemi, Y. Nikpour and M. FallahMehrjardi, Anal. Chim. Acta, 2012, 714, 89-97.

43 M. Fernández-Amado, M. C. Prieto-Blanco, P. López-Mahía, S. Muniategui-Lorenzo and D. Prada-Rodríguez, Talanta, 2016, 155, 175-184.

44 A. Mauri-Aucejo, P. Amorós, A. Moragues, C. Guillem and C. Belenguer-Sapiña, Talanta, 2016, 156-157, 95-103. 